\title{
Evidence-Based Dentistry: Goals for the Profession and Common Misconceptions
}

\author{
Barry M. Owens* \\ Department of Restorative Dentistry, University of Tennessee, Health Sciences Center, USA
}

Received: January 24, 2014, Accepted: January 24, 2014, Published: January 26, 2014

"Corresponding author: Barry M. Owens, Department of Restorative Dentistry, University of Tennessee, Health Sciences Center, College of Dentistry, 875 Union Avenue, Memphis, TN 38163, USA, Tel: 901-832-0472; E-mail: bowens@uthsc.edu

\section{Editorial}

The profession (practice) of dentistry has relied upon a somewhat "conventional" teaching model since the beginnings of formal dental education, commencing in the early nineteenth century [1]. This instructional system has incorporated a structured, balanced curriculae of didactic and clinical training with emphasis placed upon basic sciences followed by preceptorship-style clinical learning [2]. This traditional educational culture consists of University full-time "lifers" to part-time private practitioners, and/or somewhere-inbetween-ers. Technical "hand-eye" skills can be conveyed through simultaneous empirical and anecdotal knowledge, with oftentimes singular reliance upon clinical acumen of the instructor. Is this method of learning always necessarily wrong? NO...WELL PERHAPS. We as dentists' believe we are "passing on" correct skill sets to future generations, and yes, anecdotal learning can include admissions of truth and validity, while at the same time possibly just re-stating opinions. Clinical expertise is the goal of each dental practitioner, including student doctors, but, do we as experts always recognize the correct path to choose? SOMETIMES.

Dentistry, as in every health related discipline, is (and should be) a dynamic, continually evolving, blend of "Science-Based" cognitive learning and psychomotor development, and has often been referred to as "The Art and Science of Dentistry" [1,3]. In the last two decades an approach to encourage an alliance between "what is" and "what is taught" has been introduced into the medical (dental) educational system. Evidence-Based Practice in Medicine is a relatively contemporary approach to learning, first attributed to Dr. David Sackett in the mid 1990's [4]. The term can be defined as "the practice of medicine (dentistry), integrating the best available evidences with clinical experience, and allowance for patient interaction in the decision-making-treatment process. This model of learning, consists of 1) clinical expertise 2) most current research information and 3) patient communication and preferences $[2,3,5,6]$. WELL, WHAT'S NEW?

How can we apply this new-found knowledge and improve as practitioners of dentistry? In my opinion, do the best job possible, PERIOD. As a didactic and clinical instructor, I charge my student doctors to be proud of their profession and to render the best possible patient care based upon this three-tiered methodology. Does this suggest reading a peer-reviewed article and you're "good to go?"...NO. One must read (and understand) the information included in several, current, articles (usually systematic reviews and longitudinal clinical trials are the best sources of information) regarding specific techniques and/or material choices relevant to the procedures implementation (usually the formal educational "text" supplies this requirement) - however the student doctor must READ)! Does this imply sole dependence upon a stack of dental journals without incorporating one's own decision-making thought processes or judgments?...NO. As a student doctor, evaluation of one's own pre-clinical or clinical performance is an important factor for future decision-making abilities. Does this also include always accepting the instructor's guidance without pertinent inquiry or respectful questioning?... NO. We as instructors, teachers, mentors, and/or practitioners should allow interaction...That's where we learn... WE SHOULD LISTEN. Does this mean allowing the patient to exercise complete autonomy concerning the treatment phase based upon financial or immediate needs?...NO! My formal educational experience in dental school included the concept of never permitting the patient to "tell you (the practitioner) what to do regarding their (the patient's) own dental care." IS THIS WRONG?...YES. We as dentists' should allow the patient an informed voice in the "course of action"...this is INFORMED CONSENT.

Upon graduation from dental school I received some unsolicited advice from a "kindly" professor, of which included: "keep current in your profession" and "do no harm." In my opinion, these statements apply to existing teaching models as well as the assimilation of today's current concepts. We must execute our due diligence prior to patient interaction, by critical examination of the latest literature, followed by application of this knowledge through appropriate, judicious care, with allowance of patient involvement. YES.

\section{References}

1. Ring ME (1985) Dentistry: an illustrated history. Mosby-Year Book, USA.

2. Ismail AI, Bader JD (2004) Evidence-based dentistry in clinical 
practice. J Am Dent Assoc 135(1): 78-83.

3. Gillette J, Matthews JD, Frantsve-Hawley J, Weyant RJ (2009) The benefits of evidence-based dentistry for the private dental office. Dent Clin North Am 53(1): 33-45.

4. Sackett DL, Rosenberg WM, Gray JA, Haynes RB, Richardson WS (1996) Evidence based medicine: what it is and what it isn't. BMJ 312(7023): 71-72.
5. Ballini A, Capodiferro S, Toia M, Cantore S, Favia G, De Frenza G, et al. (2007) Evidence-based dentistry: what's new? Int J Med Sci 4(3): 174-178.

6. Haynes RB, Devereaux PJ, Guyatt GH (2002) Clinical expertise in the era of evidence-based medicine and patient choice. ACP J Club 136(2): A11-14. 